\title{
Three-dimensional fully coupled study of groundwater seepage and soil deformation under the action of cyclic pumping and recharge
}

\author{
Zujiang Luo ${ }^{1}$, Di Ning ${ }^{1}$, Zhao $\mathrm{Li}^{1}$, and Xiaowei Tian ${ }^{2}$ \\ ${ }^{1}$ School of Earth Science and Engineering, Hohai University, Nanjing, China \\ ${ }^{2}$ The 4th Hydrogeology Group of Hebei Bureau of Geological Development, Cangzhou, Hebei Province, China
}

Correspondence: Di Ning (1183372118@qq.com)

Published: 22 April 2020

\begin{abstract}
This study was undertaken in order to accurately analyze the land subsidence that is caused by the change in the seepage and stress fields during the pumping and recharge of groundwater. Based on Biot's consolidation theory and groundwater seepage theory (combined with theory regarding the nonlinear rheology of soil), the constitutive relationship of soil was extended to viscoelastic plastic; concurrently, considering the dynamic changes in hydraulic parameters and soil mechanical parameters, a three-dimensional fully coupled model of groundwater seepage and soil deformation was established. Using the groundwater recycling pumping and recharge test conducted by Land Subsidence Monitoring and Early Warning Center in Cangzhou City as an example, the site was divided into four loose porous aquifers. A constantly circulating pumping-recharge flow was simulated numerically, and numerical simulation was carried out on the third and fourth confined aquifers. The influence of groundwater seepage on soil deformation was analyzed, and the variation in hydraulic parameters and soil mechanical parameters were studied under the influence of the abovementioned cyclic pumping and recharge. The results show that soil deformation lags behind the change in the groundwater level, and that permanent residual deformation of soil is produced by water level fluctuations during groundwater pumping-recharge cycles. The effective porosity, the permeability coefficient and the Poisson ratio are positively correlated with the water level fluctuation in groundwater pumping-recharge cycles, whereas the modulus of deformation is negatively correlated with the water level fluctuation in groundwater during this process. All parameters change, and this change is permanent. The simulated results are in good agreement with the measured values.
\end{abstract}

\section{Introduction}

In recent years, groundwater recharge has become an emerging method for controlling the groundwater level (causing it to drop substantially) and alleviating the development of land subsidence. It uses artificial measures to inject water from surface water or other sources into the ground to fill the groundwater funnel. Recently, experts have began exploring the changing characteristics of the soil state during groundwater recharge. In a preliminary study, Zhu (1982) explored the deformation characteristics of soil mass during pumping and recharge under unidirectional osmotic pressure conditions. Su (1979) put forward the concept of the "swellshrinkage ratio" and analyzed the residual denaturation char- acteristics of each soil layer under the action of pumping and recharge. Wu and Miao (1995) and Miao et al. (1996) proposed a linear viscoelastic stress-strain constitutive model suitable for revealing the mechanics of pumping compaction and recharge expansion of the aquifer soil skeleton. Zhang et al. (2006) and Wu et al. (2009) constructed a model in which the spring body and Bingham body were connected in parallel and then another spring body was connected to the series; this model can obtain the deformation parameters of the sand layer and then, in turn, allow for the study of the trend in the variation of land subsidence. Phien-Wej et al. (1988) expounded the relationship between groundwater seepage and land subsidence using a single-well recharge test. In this paper, the stress-strain relationship of soil is extended to vis- 


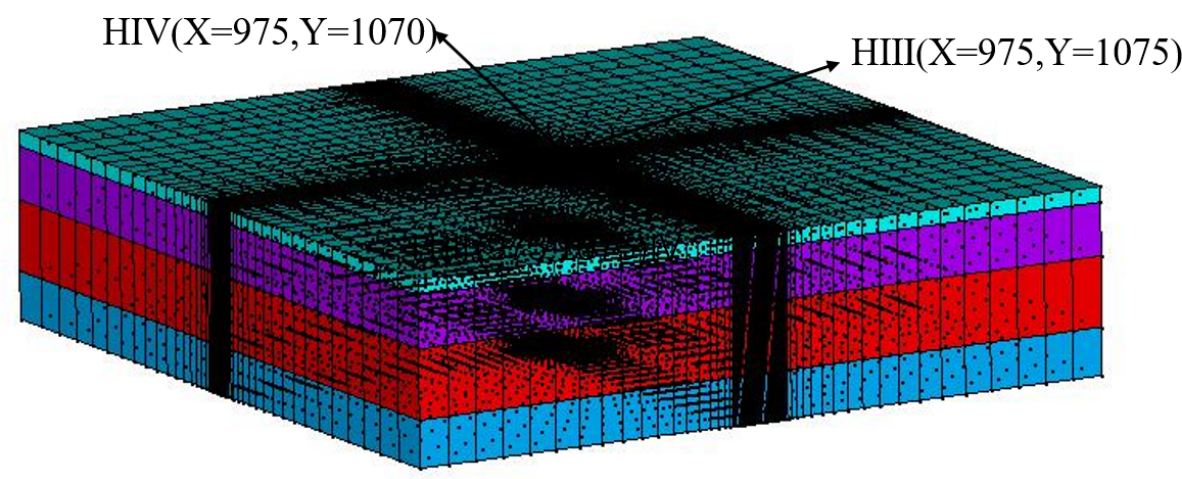

Figure 1. A three-dimensional (3-D) mesh of the model.

coelastic plasticity, a three-dimensional fully coupled model of groundwater seepage and soil deformation is established, the relationship between the aquifer water level and compressive deformation in the process of pumping and recharge is studied quantitatively, and the dynamic response mechanism of the aquifer water level and compressive deformation during the process of pumping and recharge is revealed.

\section{Fundamental theory}

\subsection{Biot's consolidation theory}

Based on the effective stress principle, Biot derived a threedimensional consolidation equation that correctly reflects the relationship between pore water pressure dissipation and soil skeleton deformation (Luo and Zeng, 2011):

$$
\left\{\begin{array}{l}
-G \nabla^{2} \omega_{x}-\frac{G}{1-2 v} \frac{\partial}{\partial x}\left(\frac{\partial \omega_{x}}{\partial x}+\frac{\partial \omega_{y}}{\partial y}+\frac{\partial \omega_{z}}{\partial z}\right)+\frac{\partial u}{\partial x}=0 \\
-G \nabla^{2} \omega_{y}-\frac{G}{1-2 v} \frac{\partial}{\partial y}\left(\frac{\partial \omega_{x}}{\partial x}+\frac{\partial \omega_{y}}{\partial y}+\frac{\partial \omega_{z}}{\partial z}\right)+\frac{\partial u}{\partial y}=0 \\
-G \nabla^{2} \omega_{z}-\frac{G}{1-2 v} \frac{\partial}{\partial z}\left(\frac{\partial \omega_{x}}{\partial x}+\frac{\partial \omega_{y}}{\partial y}+\frac{\partial \omega_{z}}{\partial z}\right)+\frac{\partial u}{\partial z}=-\gamma \\
-\frac{\partial}{\partial t}\left(\frac{\partial \omega_{x}}{\partial x}+\frac{\partial \omega_{y}}{\partial y}+\frac{\partial \omega_{z}}{\partial z}\right) \\
+\frac{1}{\gamma_{\mathrm{w}}}\left[\begin{array}{c}
\frac{\partial}{\partial x}\left(k_{x} \frac{\partial u}{\partial x}\right)+\frac{\partial}{\partial y}\left(k_{y} \frac{\partial u}{\partial y}\right) \\
+\frac{\partial}{\partial z}\left(k_{z} \frac{\partial u}{\partial z}+\gamma_{\mathrm{w}}\right)
\end{array}\right]+W=0
\end{array}\right.
$$

In the above formula, $G$ is the shear modulus; $\omega_{x}, \omega_{y}$ and $\omega_{z}$ are displacement components in three different directions; $u$ is the pore water pressure; $\gamma$ is the weight of soil; $\gamma_{\mathrm{w}}$ is the weight of water; and $k_{x}, k_{y}, k_{z}$ are permeability coefficients in three different directions.

\subsection{Biot's consolidation finite element equation}

In this study, the finite element governing equation of Biot's consolidation theory is established using the Galerkin weighted residual method, where displacement is replaced by a displacement increment in $\Delta t$, pore water pressure is expressed in its full form, and Biot's three-dimensional finite element equation is deduced. Thus,

$$
\begin{gathered}
{\left[\begin{array}{cc}
\mathbf{K} & \mathbf{C} \\
\mathbf{C}^{T} & \theta \Delta t \mathbf{H}+G
\end{array}\right]\left\{\begin{array}{c}
\Delta \delta \\
u_{i(n+1)}
\end{array}\right\}=} \\
\left\{\begin{array}{c}
\Delta F+C u_{i(n)} \\
\theta \Delta t \Delta \mathbf{Q}-(\theta \Delta t \mathbf{H}+G) u_{i(n)}
\end{array}\right\},
\end{gathered}
$$

where, $\mathbf{K}$ is the infiltration flow matrix, $\mathbf{C}$ is the elastoplastic flexibility matrix, $\Delta \delta$ is the joint displacement increment, $\Delta F$ is breaking the increment of the criterion function, $\Delta \mathbf{Q}$ is the traffic increment matrix, $\mathbf{H}$ is the water level matrix and $\theta$ is the lode angle.

A fixed head boundary is used in the simulation. The initial displacement value is set to zero, and the displacement of the three directions is also zero in this simulation. According to the abovementioned mathematical model (solving the model using the Galerkin finite element method), a three-dimensional fully coupled numerical analysis program for groundwater seepage and soil deformation has been developed using the Fortran 95 language.

\section{Application example}

\subsection{Conceptual model}

The study area is located in the urban area of Cangzhou City, Hebei Province. The terrain is low and flat. A four-layer aquifer model with a length of $2000 \mathrm{~m}$, a width of $2000 \mathrm{~m}$ and a height of $400 \mathrm{~m}$ is established. This four-layer model can be divided into four aquifer groups according to the layer order from top to bottom. The first aquifer formation is from the Holocene, its floor is $30 \mathrm{~m}$ deep, and its lithology is dominated by fine sand and silt. The second aquifer formation is from the Upper Pliocene, its floor is $170 \mathrm{~m}$ deep, and its lithology is mainly medium sand and coarse medium sand. The third aquifer group is from the Middle Pleistocene, its floor is $290 \mathrm{~m}$ deep, and its lithology is mainly sub-clay and clay. The fourth aquifer group is from the Pleistocene, its floor is $400 \mathrm{~m}$ deep, and the lithology is mainly sub-clay and clay. An eight-node hexahedral element is adopted for dis- 
Table 1. Parameter zones and values.

\begin{tabular}{|c|c|c|c|c|c|c|c|c|c|c|c|c|}
\hline \multirow[t]{2}{*}{$\begin{array}{l}\text { Parameter } \\
\text { Zones }\end{array}$} & \multicolumn{3}{|c|}{$\begin{array}{c}\text { Hydraulic } \\
\text { conductivity }\left(\mathrm{m} \mathrm{d}^{-1}\right)\end{array}$} & \multirow[t]{2}{*}{$\begin{array}{l}\text { Specific } \\
\text { yield } \mu\end{array}$} & \multirow{2}{*}{$\begin{array}{r}\text { Specific } \\
\text { storage } S_{\mathrm{S}} \\
\quad\left(\mathrm{m}^{-1}\right)\end{array}$} & \multirow{2}{*}{$\begin{array}{r}\text { Deformation } \\
\text { modulus } E \\
\text { (MPa) }\end{array}$} & \multirow[t]{2}{*}{$\begin{array}{r}\text { Poisson } \\
\text { ratio } v\end{array}$} & \multirow{2}{*}{$\begin{array}{r}\text { Cohesive } \\
\text { force } c \\
(\mathrm{KPa})\end{array}$} & \multirow{2}{*}{$\begin{array}{r}\text { Friction } \\
\text { angle } \varphi \\
\left({ }^{\circ}\right)\end{array}$} & \multirow{2}{*}{$\begin{array}{c}\text { Expansion } \\
\text { angle } \psi \\
\left({ }^{\circ}\right)\end{array}$} & \multirow{2}{*}{$\begin{array}{l}\text { Severity } \\
\text { of soil } \gamma \\
\left(\mathrm{kN} \mathrm{m}^{-3}\right)\end{array}$} & \multirow[t]{2}{*}{$\begin{array}{r}\text { Effective } \\
\text { porosity } n\end{array}$} \\
\hline & $K_{x}$ & $K_{y}$ & $K_{z}$ & & & & & & & & & \\
\hline 1 & 5 & 5 & $5 \times 10^{-5}$ & 0.06 & & 22.36 & 0.47 & 6.5 & 17 & 0 & 20.73 & 0.351 \\
\hline 2 & 3.5 & 3.5 & $1 \times 10^{-5}$ & & 0.00078 & 22.79 & 0.47 & 6.2 & 20 & 0 & 20.03 & 0.350 \\
\hline 3 & 9 & 9 & $1 \times 10^{-5}$ & & 0.00035 & 23.48 & 0.47 & 6.5 & 21 & 0 & 20.68 & 0.340 \\
\hline 4 & 5.5 & 5.5 & $1 \times 10^{-5}$ & & 0.0001 & 23.54 & 0.47 & 6 & 21 & 0 & 21.04 & 0.328 \\
\hline
\end{tabular}

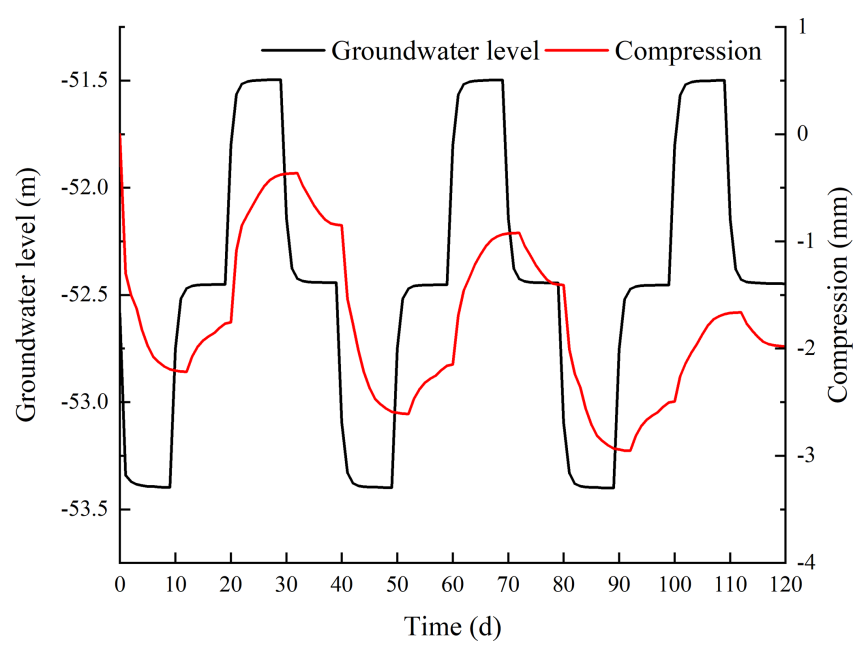

Figure 2. Compressed volume and water level with stress period in the third confined aquifer group under the first pumping and recharge scheme.

cretization. The plane is divided into 3672 units, which results in a total of 14688 units. Each layer is a parameter partition, which results in a total of four parameter partitions. The boundary of the model is generalized to a definite head boundary, the bottom of which is an impermeable boundary, and there is no hydraulic connection between the bottom of the model and the aquifers. The three-dimensional mesh of the model is shown in Fig. 1, and the zones and values of the parameters are shown in Table 1.

\section{Model computation and analysis}

\subsection{Settlement calculation and analysis}

Three rounds of pumping-recharge cycles are carried out in the model. Each round is divided into four stages, totaling 12 stages, and each stage has the same time step. The first scheme uses $10 \mathrm{~d}$ as a stress period and one stress period is a time step, resulting in 12 stress periods. The second scheme uses $100 \mathrm{~d}$ as a stress period and one stress period as a time step, resulting in 12 stress periods. Pumping wells and recharging wells have the same well locations, which are located in the third and fourth aquifer groups, respectively; the

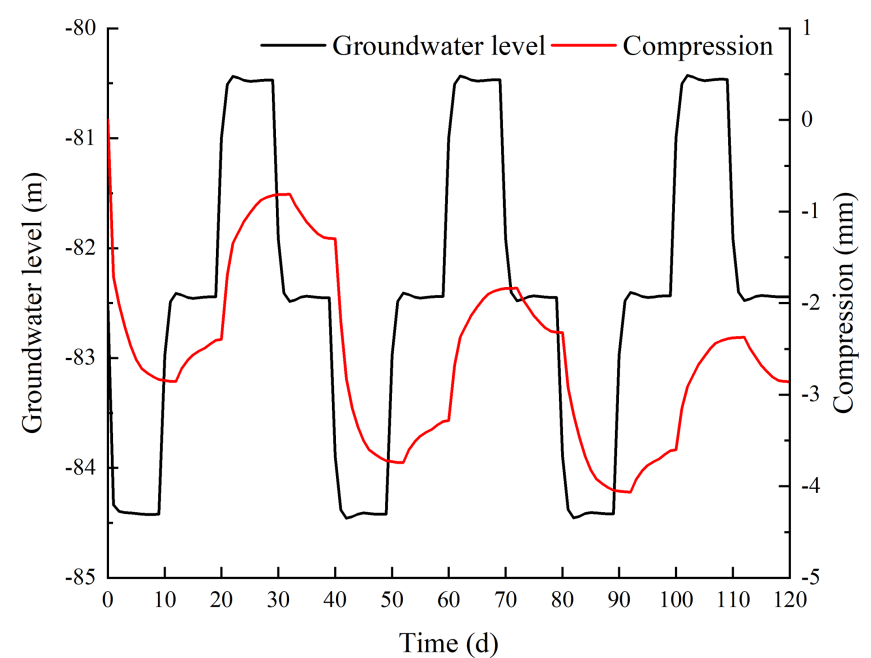

Figure 3. Compressed volume and water level with stress period in the fourth confined aquifer group under the first pumping and recharge scheme

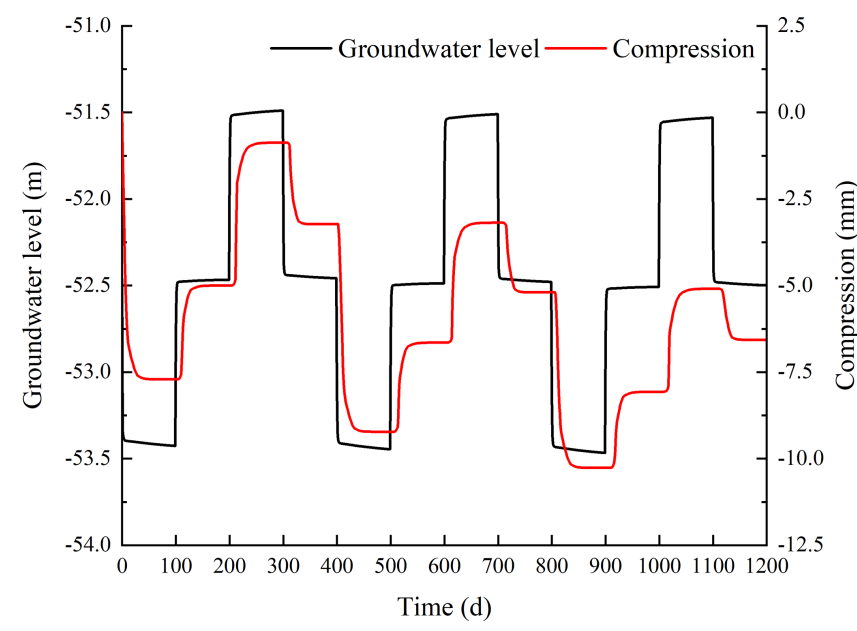

Figure 4. Compressed volume and water level with stress period in the third confined aquifer group under the second pumping and recharge scheme.

wells are referred to as "Well HIII" and "Well HIV", and the two wells are in unit 9959 and unit 13575 , respectively. The pumping time is the first stress period, the fifth stress period 


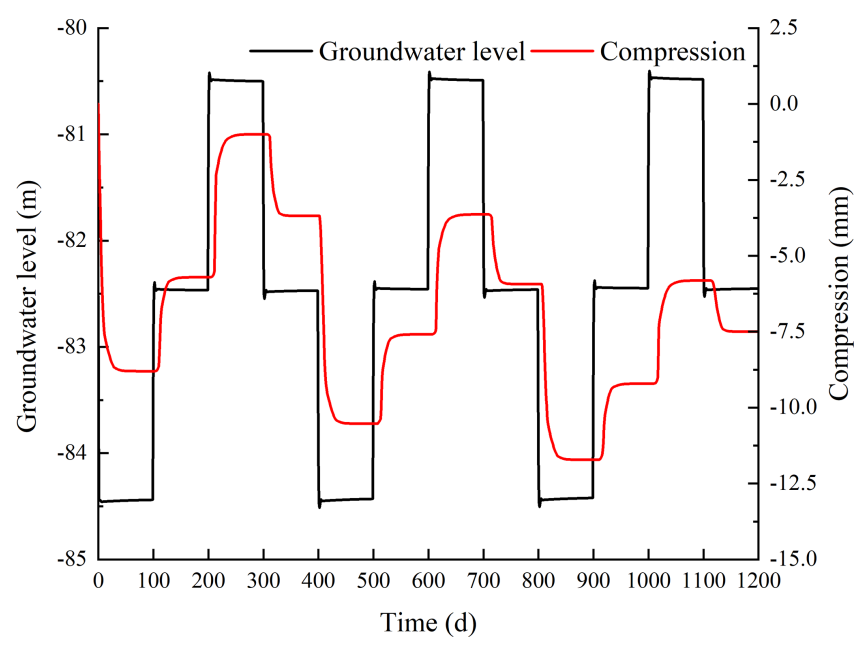

Figure 5. Compressed volume and water level with stress period in the fourth confined aquifer group under the second pumping and recharge scheme.

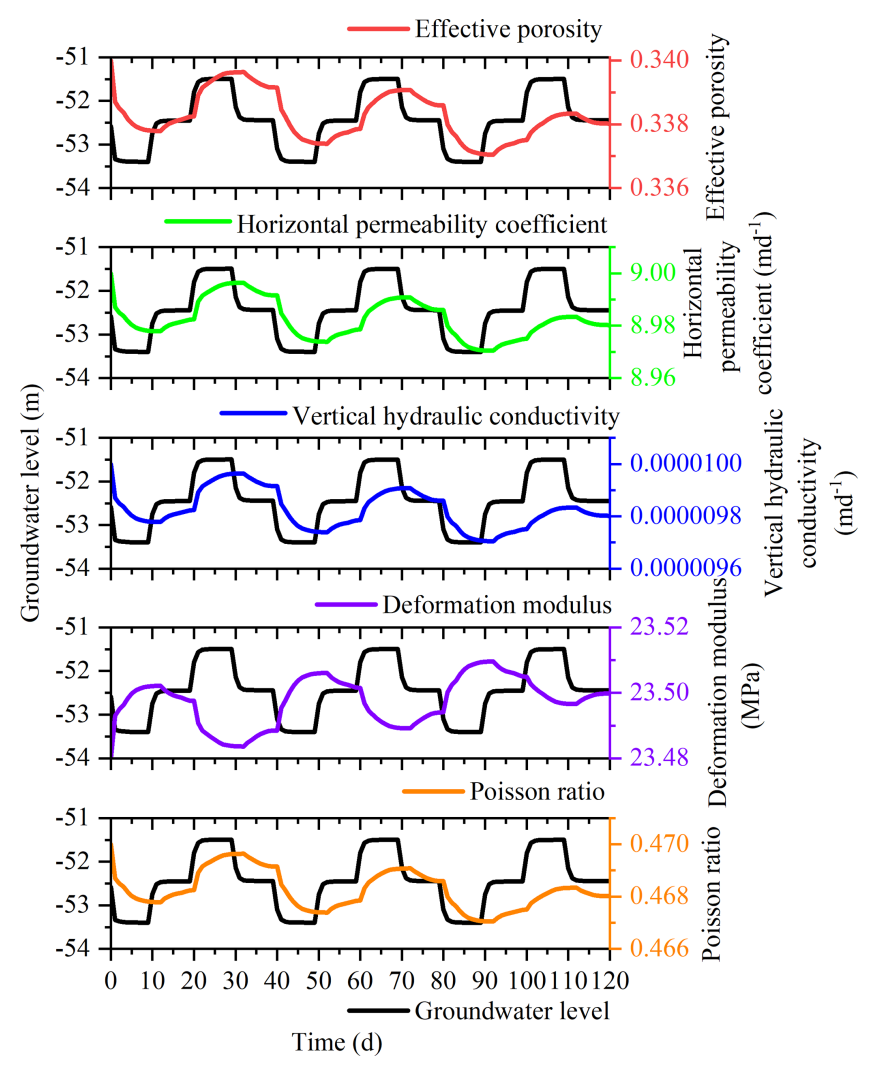

Figure 6. Parameter and water level with stress period in the third confined aquifer group under the first pumping and recharge scheme.

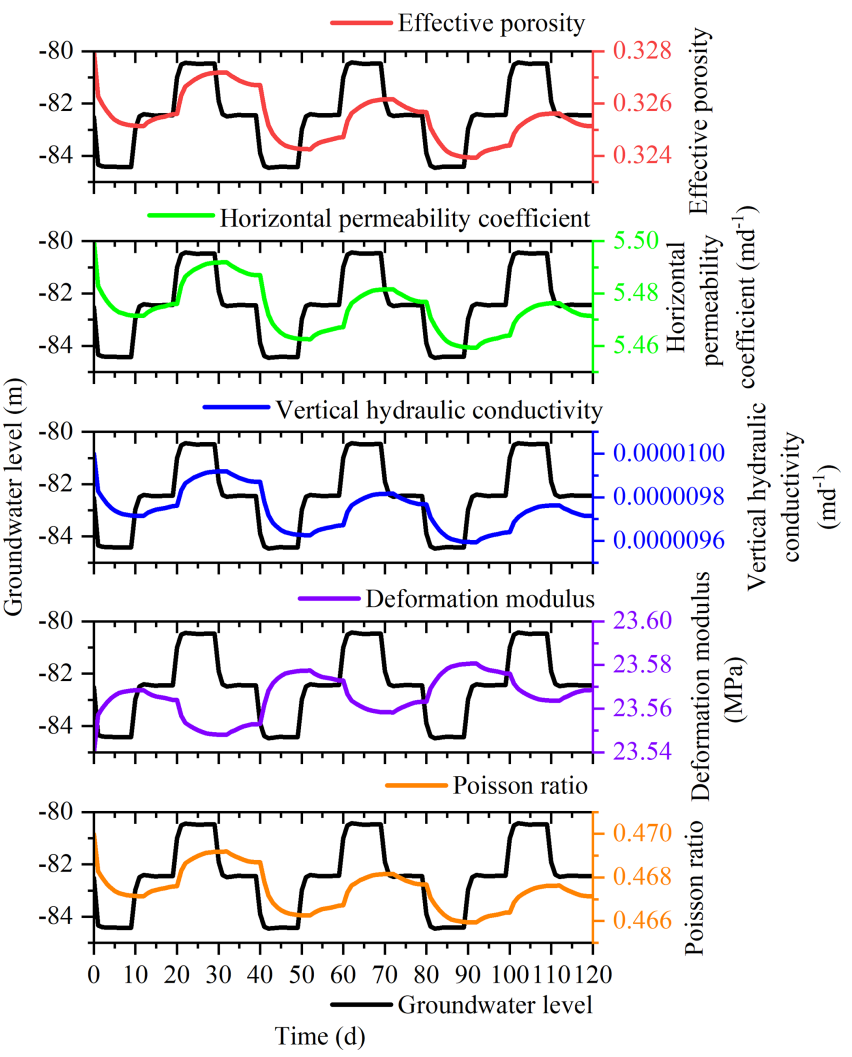

Figure 7. Parameter and water level with stress period in the fourth confined aquifer group under the first pumping and recharge scheme.

and the ninth stress period; the recharging time is the third stress period, the seventh stress period and the eleventh stress period. During the remaining stress periods, wells HIII and HIV are closed and the water level is restored. The singlewell pumping and recharging water flow is $200 \mathrm{~m}^{3} \mathrm{~d}^{-1}$.

The compression and water level of the third and fourth aquifers under the two pumping and recharge schemes vary with stress period as shown in Figs. 2-5.

\subsection{Calculation and analysis of parameters}

During the pumping and recharge process, the seepage field of groundwater, the state of soil, and the mechanical properties all change accordingly. Whether the dynamic change process of the parameters corresponds to the consolidation process of soil depends on the correctness of the model. The calculation results from the model are pore water pressure. The parameters and the groundwater level with respect to stress period under the two pumping-recharge schemes are shown in Figs. 6-9. 


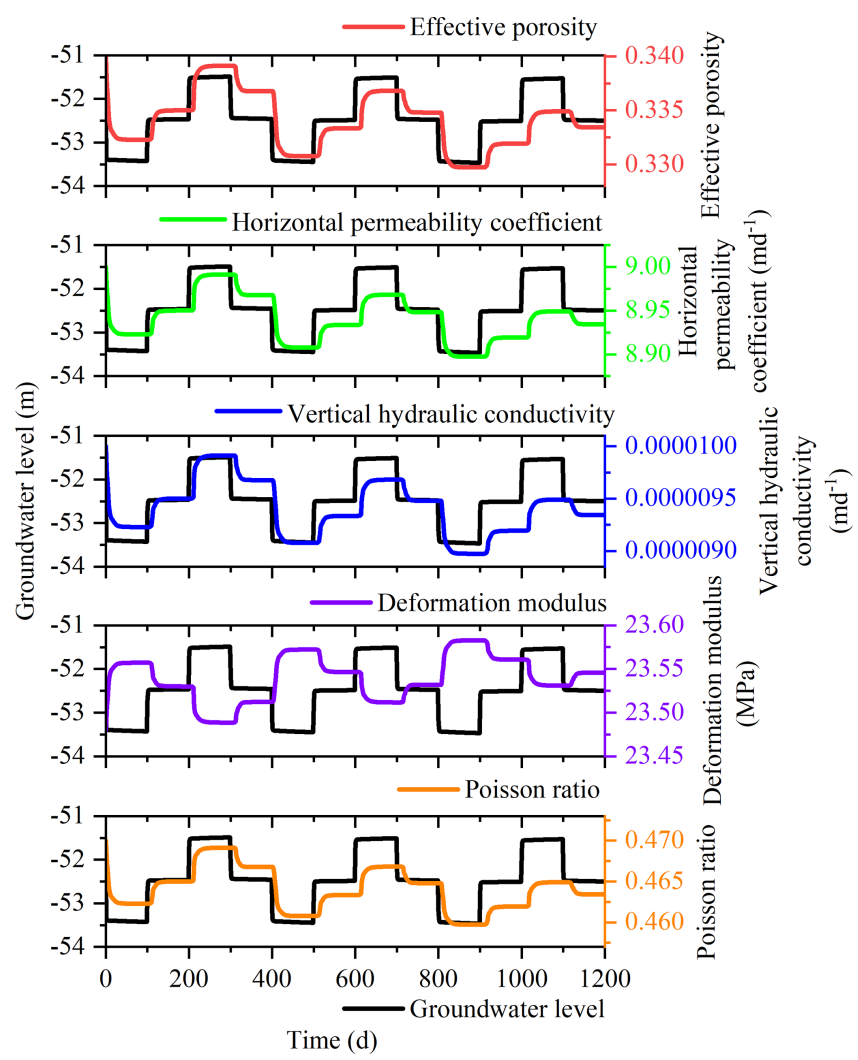

Figure 8. Parameter and water level with stress period in the third confined aquifer group under the second pumping and recharge scheme.

\section{Conclusions}

The main outcomes of this work are as follows:

1. Based on Biot's consolidation theory, a threedimensional fully coupled model of groundwater seepage and soil deformation is established that fully considers the changes in the groundwater seepage field and soil mechanical parameters during soil deformation. The calculation results of this model are in line with the real situation, and its accuracy is better than other numerical models.

2. The soil deformation calculated by the threedimensional fully coupled model of groundwater seepage and soil deformation lags behind the change in the water level. After the three pumping-recharge cycles, the water level is restored to the initial water level, and there is residual settlement of the soil layer, which is in accordance with the actual situation.

3. The trend in the variation of the effective porosity, the permeability coefficient, the deformation modulus and the Poisson ratio corresponds to the deformation trend in soil. The groundwater level changes periodically with

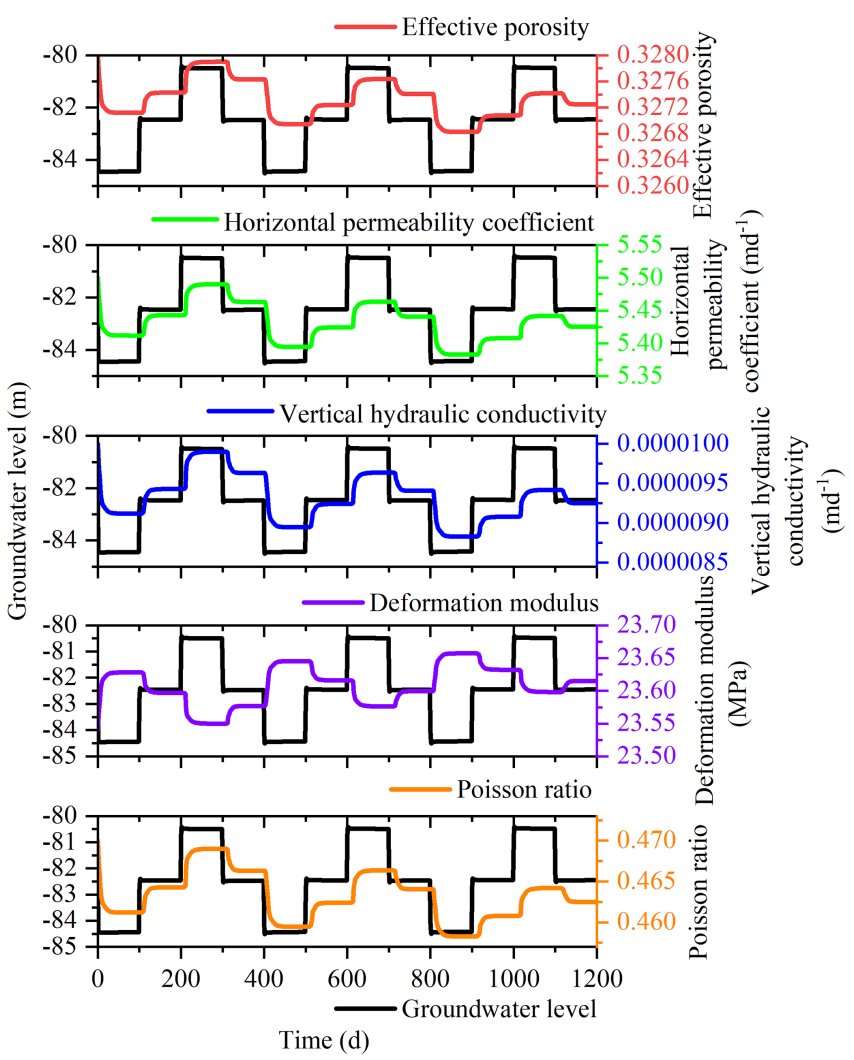

Figure 9. Parameter and water level with stress period in the fourth confined aquifer group under the second pumping and recharge scheme.

the development of pumping and recharge: first decreasing, restoring and rising, and then rising, restoring and falling. Soil deformation shows a trend where it first compresses and then rebounds. The total trend in the variation of the effective porosity, the permeability coefficient and the Poisson ratio first decreases and then increases. The overall trend in the variation of the deformation modulus increases first and then decreases. However, all parameters lag behind the change in groundwater level.

Data availability. As this research is ongoing, the data are currently not available to the public.

Author contributions. ZL contributed to the conception of the study; DN performed the data analyses and wrote the paper; ZL contributed significantly to the analysis and paper preparation; XT helped perform the analysis by participating in constructive discussions.

Competing interests. The authors declare that they have no conflict of interest. 
Special issue statement. This article is part of the special issue "TISOLS: the Tenth International Symposium On Land Subsidence - living with subsidence". It is a result of the Tenth International Symposium on Land Subsidence, Delft, the Netherlands, 17-21 May 2021.

Financial support. This research has been supported by the National Natural Science Foundation of China (grant no. 41874014) and the China Ministry of Natural Resources project (grant no. A191001).

\section{References}

Luo, Z. J. and Zeng, F.: Finite Element Numerical Simulation of Land Subsidence and Groundwater Exploitation Based on Viscoelastic-plastic Biot's Consolidation Theory, J. Hydrodynam., 23, 615-624, 2011.

Miao, J. F., Wu, L. G., and Duan, G. X.: The Mechanism of Soil Deformation due to Pumping \& Recharging, Shanghai Geol., 1, 10-15, 1996.

Phien-Wej, N., Giao, P. H., and Nutalaya, P.: Field experiment of artificial recharge through a well with reference to land subsidence control, Eng. Geol., 50, 187-201, 1988.

$\mathrm{Su}, \mathrm{H}$. Y.: Investigation of the Deformation Characteristics of Various Soil Stata under the Influence of Pumping out \& back of Groundwater in Shanghai, Chinese J. Geotech. Eng., 1, 24-35, 1979.

Wu, J. Z., Wang, H. M., and Yang, T. L.: Experimental Research on Artifical Recharge to Shallow Aquifer to Control Land Subsidence due to Construction in Shanghai City, Geoscience, 23, 1194-1200, 2009.

Wu, L. G. and Miao, J. F.: Soil Layer Deformation and Determination of the Constitutive Law on the Stress-Strain of Soils under Pumping-Recharge, Earth Sci., 5, 581-588, 1995.

Zhang, Y., Xue, Y. Q., and Wu, J. C.: Characteristics and Parameters of Sand Strata Deformation Due to Groundwater Pumping in Shanghai, J. Hydraul. Eng., 5, 560-566, 2006.

Zhu, L. M.: Preliminary Study on Deformation Characteristics of Soil under Pumping Recharge, Shanghai Geol., 2, 45-46, 1982. 